\title{
The Decentralizing and Democratizing Effects of Digitalization on Media Industries
}

\author{
Jieru Zhang \\ Communication University of China \\ Beijing, China 100024
}

\begin{abstract}
Digitalization has had an indisputable impact in terms of democratizing and decentralizing on media industries. This article introduced how the internet was generally regarded as a symbol of digitalization. Followed by discussed to what degree digitalization can be seen as having a democratizing and decentralizing effect on the media industries from four key aspects.
\end{abstract}

keywords-Media Industries; Decentralizing; Democratizing; Digitalization

\section{INTRODUCTION}

In 2006, Time magazine named its Person of the Year as "YOU"; by doing so the magazine recognized the efforts of millions of anonymous users who made great contributions to the Internet. This praise was given in recognition of the huge quantities of user-generated content (UGC) that internet contributors upload to a wide variety of information-sharing sites such as Facebook, YouTube and Wikipedia (among others). The award represents an increasing awareness of the changing nature of the digital world and how the internet has begun to decentralize and democratize the media of the $21^{\text {st }}$ century.

To begin with I will discuss the phenomenon of decentralization and democratization in the digital age. I will then go on to describe the effects this democratization and decentralization has had on various aspects of the media industries. Finally, I will analyse the extent of the change that has occurred in the media industries, and what influence digitalization has had on said industries.

\section{The Rise of Digitalization: The SECOND Media AGE}

The most remarkable change which the rise of digitalization has brought to the media industries, and to human society as a whole, is the popularization of internet. From the early nineties the internet has developed at an extremely rapid pace, and the rise of digitalization has helped bring about this rapid growth. The evolution of communication and the dissemination of technology provided the public an unprecedented level of access to information; such a technological revolution connected people in ways previously impossible, allowing people to communicate across oceans instantly and learn about events within seconds of their happening. As such, traditional media industries have had to evolve to adapt to the digitalized world, and the effect the internet has had on such industries cannot be understated. This essay will examine the internet and discuss the democratizing and decentralizing effects which digitalization has brought to the media industries.

The first media age was characterised by three attributes: highly centralized information, one-way communication and the treatment of the audience as a uniform entity (Holmes, 2005). The second media age, as defined by Mark Poster (1995), is marked by the development of digital techniques and the democratization and decentralisation of the media industries. Trevor Barr has had some unique insights on the democratic influence of digitalization; according to Barr, in the age of digitalization the anarchy of the internet has begun to supersede the centralized control of traditional media (Barr, 2000). He described print journalism, broadcasting and other pre-digitalization age media industries as the "gatekeepers" of text and content; these gatekeepers do not exist on the internet.

People can re-define themselves on the online virtual space; they can express their own personality and share their thoughts and ideas with other users. This aspect of digitalization was also identified by Poster (Poster, 1995). He suggested the effect of democratization on the progress of digitalization could be seen in a digital space like the internet, where individuals can avoid the limitations of social classes, race and gender.

Decentralization is another notable feature of digitalization. Negroponte (1995) supports the notion that decentralization is an important sign of what he called the 'post-Information age'. Poster (Poster, 1995) described the decentralizing effect the internet had on the media industries like so:

"The magic of the Internet is that it is a technology that puts cultural acts, symbolizations in all forms, in the hands of all participants; it radically decentralizes the positions of speech, publishing, filmmaking, radio and television broadcasting, in short the apparatuses of cultural production" (p. 222). Because digital media has adopted interactive communication, digitalization brings a democratizing and decentralizing influence to both consumers and media enterprises. In the following section this article will analyse this phenomenon in regard to the following aspects: the participation of consumers, the personalized and diversified 
development of media industries and the transformation of consumer requirements and media industries.

\section{PARTICIPATION OF CONSUMERS}

The impact of digitalization on the consumer can principally be seen in the participation of consumers. Since the development of digitization and the Internet there has been a paradigm shift, as the days of production centrality and consumer one-way acceptance ended with the last days of the first media age (Livingstone, 2004). The qualification of the user has been studied more intensely by media scholars in past few decades. Henry Jenkins points out that consumers have been increasingly empowered by new technologies; they are "occupying a space at the intersection between old and new media. And demanding the right to participate within the culture" (2006, p. 24). In the book Blogs, Wikipedia, Second Life and Beyond: From Production to Produsage, Australian scholar Bruns Axel introduced the portmanteau "produsage", a combination of the words "production" and "usage". The notion of "produsage" is based on online platforms such as YouTube and Facebook, and describes how the role of consumer and producer have begun to merge as internet users take on both roles simultaneously (Bruns, 2008).

Wikipedia is characteristic of this phenomenon, with consumers of information having a central role in producing it. In Wikipedia, the content authors are not elites and experts (as in the case of traditional encyclopaedias), but regular users of the website who have been given the right to write, edit and revise entries. As of July 2014, the English edition of Wikipedia has 4.54 million entries which have been edited by millions of anonymous users from all around the world. All text, images and other content on Wikipedia is published through the GNU Free Documentation License, an open protocol of anti-copyright content which ensures the freedom and openness of content. All content produced by users on Wikipedia has to comply with the copyleft agreement, which means all the content from Wikipedia can be copied and disseminated without limit. Web2.0 websites, such as Wikipedia, are continually breaking down barriers between consumption and production and the line between professional and amateur; this has resulted in a revolution in consumer participation.

There has been an increasing participation of users in other media industries. For example, in the digital age, journalism has begun to focus on the efficiency of obtaining information rather than the sourcing of said information; many professional new outlets have begun to use social media as a means for acquiring information, with many stories being broken by consumers rather than reporters. Several journalists are now using computer programs to monitor social media for new stories and fresh sources of information, with a particular eye towards verified accounts of celebrities, opinions on organizations and trending topics which are popular with the public. These tactics are already helping journalism to evolve with the times and report information at the pace that modern consumers expect, providing multiple perspectives and first-hand reporting.
In additional, in the game industries, gamers are contributing content; this marries the roles of gamer and creator, and blurs the line between producer and consumer. According to the statistics, users of The Sims created nearly $90 \%$ of the game content (Herz, 2005).

Several media industries have started to implement consumer participation as a means for production and development, with the 3D sandbox game Minecraft being an excellent example of this. As an independent video game, Minecraft was developed by Mojang, a small game company, and was distributed by entirely digital means. During its development, the game did not have financial support from large game publisher, instead relying on a beta-release and consumer funding to support development. The game design focused more on user experience and innovation and less on graphics; the retro look of the game eschews the trend of high-end graphics and linearity which modern releases tend towards. This game applies the JAVA programming language which results in it having a "low resolution" and "LEGO" style of image quality (Mojang, 2015). However, one of the most important characteristics of Minecraft is the distinct lack of plot, and the game feels more like a piece of design software which allows for extensive user participation the creative input of users. In the Minecraft, the core tasks of players are 'mining' and 'crafting' various virtual materials. Then players can use these materials to build objects and structures according to their whims and imaginations.

Minecraft's selling point seems to extend beyond that of traditional games; rather than selling a premade experience, Minecraft offers a world in which a player can craft their own experience. To some degree, Minecraft just provides a structure upon which players create the content. Thus, the participation of players in Minecraft has reached unprecedented level, with its emphasis on consumer participation fuelling is success and popularity; as of October 2014 Minecraft has sold over 60 million copies, making it one the most popular games of all time (Time, 2014).

In addition, the digital business model also attracts publicity for products and acts as another means of marketing. Players have an opportunity to design the website and forum dedicated to showcasing pictures, comic books, clothing and other peripheral products related to Minecraft (Lastowka, 2012). At these sites, gaming enthusiasts can exchange their experiences and stories. As many games have not provided an environment for the digital community to converse, many players share their work on YouTube, Facebook and other social networking sites, all of which attracts more people to participate in the game. In the process of digitization of the product, the user becomes a game advocate who replaces the traditional marketing channels, providing publicity and promotion for the game through their participation in it.

The case of Minecraft shows that the emphasis of computer game development has already shifted from precrafted, structured games constructed by game designers, towards a more open-world, open-ended model, where the game companies provide the environment in which users can create their own content and mould their own experience. 


\section{PERSONALIZED AND DIVERSIFIED DEVELOPMENT OF MEDIA INDUSTRIES}

This second section will discuss how the democratizing and decentralizing effects of digitalization have made media production and consumer requirements more personalized and diversified.

Even academics who are non-specialists, like Manuel Castells (1996), have adopted a variation on the second media age thesis in a critique of McLuhan. Castells and others argue that rise of cable and digital television audiences in television has effected a more interactive and intimate media culture. While the world of McLuhan had been one of unidirectional communication, the new age has brought about an era of interaction, where audiences have a vast expanse of raw material to choose from.

In contrast to mass communication, digital media does not use one-way communication, but uses interactive communication instead; this means that not only does the media act upon the audience, but the audience also reacts to media, and users can edit, amend or recombine information to fit their needs. In traditional media forms, like print journalism and broadcasting, users can only choose from a limited range of options. In digital media industries users not only have more choices, but also can change the content and form of communication to better fit their tastes. Because the consumer participates in the process of communication, the initiative of consumer also influences the communication itself; as characteristic of the digital age, this form of interaction has been regarded as adding value to media (Lister et al., 2009, cited in Miller, 2011, pp.13). As noted above, this interaction has made consumer feedback more potent in the creation of content and the formatting of communication. This new relationship has resulted in more complex consumer feedback, extending far beyond the former systems of feedback (which merely amounted to approval or disapproval). Media enterprises can therefore better understand the requirements of consumers through this extensive interaction. Media enterprises can adjust products based on market feedback and more effectively attract consumers through targeted marketing and development. In short, interactive communication not only allows consumers to access information from multiple channels and multiple forms, but also allows media industries to manufacture products with multiple types, with greater coverage and relevance, by listening to consumer feedback.

New media communication has established each individual as their own entity, distinct from "mass" audience. Online, everyone can create their own media according to their own needs; this personalization of online media has cultivated an increased self-awareness and resulted in more personalized demands.

These new, more nuanced demands are breaking down traditional media forms. The media industries have entered a "niche age". At the beginning of the digital media age, there was a constant increase in both the variety and quantity of content available, offering consumers more choice. However this generated an audience too busy to focus on useless information, as they were barraged with a huge amount of content. In response to this, digitalization led to more interaction with consumers, and resulted in personalized content to fit personalized demands; Web 2.0 is an excellent example of this kind of tailored demand. In the new digital age, media products have begun to easily communicate "through the use of automated templates and algorithms"; this means there are several media objects that have been independently produced by software, as opposed to being produced by humans. As mentioned earlier, this transformation has blurred the boundary between producers and consumers, and results in more targeted media products. Websites collect personal user information through cookies, then use algorithms to analyse this information to predict user behaviour; this can which can help media companies target services or products to consumers. For example, users can often see advertisements relating to content they have previously searched. Amazon, the online shopping website, adjusts its pages according to users' purchase history in order to recommend other products (Bruns, 2007). Social media websites like Facebook have demonstrated the success of the "suggestion" service, which is based on a user's friends list and suggests people the user may know. ITunes also recommends music similar to the music which users have in their library or listen to.

Another change brought about by the digitalization is diversification of media text, and the use of databases as a means of media product diversification.

A database can be considered a 'structured collection of data' (Manovich, 2001, pp.218), or a 'container of information' (Paul, 2007, cited in Miller, 2011, p.20). Even prior to the advent of computing technology databases have existed; libraries, archives, books and even human experts can all be considered types of database, as all collect and sort information so that it can be accessed later (Paul, 2007 cited in Miller, 2011, p.20). According to this definition, the internet itself is a database, with the websites and online systems that it consists of all being smaller databases in their own right. Manovich suggests that this is a trend, and that databases have become the dominant cultural denominator of the $21^{\text {st }}$ century; 'almost every practical act involves choosing from some menu, catalogue or database' (Manovich, 2001, p. 128).

This trend be seen in almost every aspect of our lives; the list of links on a web page, the lists on the home menu of a DVD, the personal traits listed on a social media profile, the pages brought up by a search engine. The commercial giants of earlier days may have made their wealth from resources, now companies make their money from databases; businesses like Google, Yahoo!, Amazon, eBay and Microsoft have all made billions from services which provide, sort and access databases. Even webpages, the constituent units of the internet, are not the coherent entity their visuals suggests; beneath every page lies databases of elements, text, images and sounds, all of which are stored and assembled on demand (Manovich, 2001).

The huge database that is the internet allows users to upload and share text, images and sounds to others; at the same time, users can also acquire more resources for 
themselves. In this case, the music industry is an excellent example of this.

The internet has blown the music industry wide open; on one hand it allows small artists and producers to attract an audience and gain exposure, and on the other it enables the pirating of music, hurting both artists and music labels, meaning that smaller artists may have to compete more intensely for the money people are willing to pay.

Music streaming is another force of nature the internet has thrown at the music industry, as paid downloads have plummeted in recent years. Just as the music industry had begun to adjust to the digital download market (as opposed to the CDs of earlier years), music subscription services have become the new norm, allowing users instant access to millions of songs for a small fee. Although this new form of listening does provide exposure and income to artists, the royalty rates of streaming are much lower than that of $\mathrm{CD} /$ vinyl/digital download sales, and means that artists and labels have to struggle to turn a profit.

\section{TRANSFORMATION OF CONSUMER'S REQUIREMENTS AND MEDIA INDUSTRIES}

In the pre-digitalization age, consumer feedback was often just a variable which the media companies used to evaluate sales or profits and to develop marketing methods. However, for media enterprises, the revolution of digitalization has increased the influence of consumer feedback to a whole new level. In December 2014, the Chinese movie "Gone With The Bullets" was officially released, and it was the first movie in China to be released online and offline simultaneously.

The movie is an adaption of a famous murder case and it had huge amounts of money invested in it, a well-known director and an all-star cast. The simultaneous online and offline release was a cross-border deal between traditional media industries and internet companies; as such "Gone With The Bullets" has been considered an attempt at transforming traditional media. Before the film was released, there was a large amount of news coverage, and several media industry insiders predicted the film would bring in between 1.5 and 2 billion RMB at the box office, a new box office record. But after the first day of the premiere, most of online comments were negatively. The film even was given an average score of 6.4 (with a maximum of 10) by some film review websites, with public participation being accounted for in the score. Social media websites were filled with spoof and parody videos. According to the studio estimates, the final income of film will struggle to break 600 million RMB. It is a typical case which shows that audience feedback can directly affect media product marketing. Consumer feedback for media industries in the digital age are much more important than in the broadcasting age.

In addition, democratizing and decentralizing effect of digitalization has resulted in traditional media magnates losing their power; this phenomenon is extremely important to. Jenkins (1992) has indicated that the internet provides consumers with adequate power and technology to evaluate and re-establish the relationship between themselves and media companies. This democratizing and decentralizing influence means that the media has struggled to control the consumer's choice, as the consciousness of consumers of themselves have been revived. The traditional media authority over consumers is disappearing and the relationship between consumers and media companies has shifted one of consumers being passive and submissive to consumers being active and dominant. As previously mentioned, the interactive communication network that digital technology has brought has provided users with more choice. Since 2007 to 2010, the internet has shown a steady rate of growth, while traditional media industries like print journalism are in decline. According to the survey of Pew Research Centre in 2013, among the sample surveyed around 38 percent people read newspapers; if the survey counted people who read newspapers online, the proportion rose to 43 percent. Of them, 4 percent of people read both online and offline newspapers and 9 percent only browsed online news. Furthermore, newspapers have developed online versions in order to effectively attracted younger readers. The survey also showed that more 18 to 24 year olds read newspapers today than ten years. On the other hand, among newspapers readers, most of them only read local newspapers and fewer read the New York Times ( 2 percent), the Washington Post ( 2 percent) or USA Today ( 3 percent); however, when online readers were included these figures rose to 18 per cent, 9 per cent and 7 per cent. This data shows that if traditional media wants to develop in the future they have to adapt to digital technologies, such as digital broadcasting, e-journals, mobile phone newspapers and mobile $\mathrm{TV}$, in order to better communicate with consumers. In a word, the digitalization of the media has resulted in the transformation of consumer behaviour, and this change in consumer behaviour has further stimulated the consuming market. Therefore, media enterprises have adjusted their marketing strategies to promote their products and the services they provide, and this accelerates the digitalization process of traditional media and the development of new media.

There are two main strategies that media companies use to adapt to digital platforms; the establishment of an internet presence and the integration of new media. In recent years, as internet technology develops, traditional American newspaper industries have begun to actively promote the transition from paper printing to the electronic press. One of the main reasons that traditional media have lost their consumers is that communication methods of online media more attractive to consumers than traditional media communication methods.

In 1996, the New York Times created its own website which profited from its first year, and it now has more than fifty million unique views per month. The growth of online users at a rate of 30 to 40 percent means that the New York Times is fast becoming the most influential newspaper website. On their webpage, if a user clicks on a news picture, the page will immediately provide links to other dozens of other pictures, videos and written reports which are relative to the previous piece. In 2005, the New York Times purchased About.com (Seelye, 2005), one of the ten most popular portal websites. Its purchase heralded the New York 
Times official entry into the domain of social media. After the introduction of a Web 2.0 tool, the popularity of the online version of the New York Times is steadily growing, and the paper is entering the era of digitalization.

\section{THE LIMITATION OF DEMOCRATIZING AND DECENTRALIZING INFLUENCE}

However, there are some researchers who claim that the democratizing and decentralizing influence which digitalization has brought to the media industries has been overstated. Some of them pointed out that the term "participation" is relatively vague. A report from CNET asserted, even for Web 2.0, which claims to combine on social communities, user engagement was often worse than they had expected. Analyst Bill Tancer from Hitwise, an online audience survey company, indicated that only 0.16 percent of YouTube users uploaded videos for others to the site. Only around 20 percent of users from the Yahoo! picture-sharing site, Flickr, uploaded photographs on it, with most of users just browsing content like traditional TV audiences (Tancer, 2007).

There seems to be a new emerging trend in internet interactivity; while 100 people may gather online, only 1 will create content, 10 will interact with it and the remaining 89 will just watch it (Arthur, 2006). If there are so few creators and influencers of content, what is the nebulous term 'participation' referring to? A better way of understanding it may be to look at the different levels of participation; a recent American survey characterises user behaviour according to six levels of participation on a so-called 'participation ladder'. It showed that of all the users of usergenerated content websites, $13 \%$ were 'active creators' (those who create content like blogs, videos or images), $19 \%$ were 'critics' (those who rated or evaluated content), $15 \%$ were 'collectors' (those who save and share URLs on social bookmarking services) and 19\% were 'joiners' (those who joined social networking websites like Facebook or MySpace, but didn't necessarily produce anything). Most users, however, were either 'passive spectators' (33\%) or 'inactives' (52\%); passive spectators would watch videos or read blogs, while inactives would not participate in any of these activities. This study makes it clear that 'participation' does not equate to 'contribution' on the internet; when we talk about participation we are talking in relative terms, as over $80 \%$ of all users are passive recipients (OECD, 2007).

On the other hand, some people have argued that the power of traditional media centres has just been weakened; this does not mean digitalization will cause the entire collapse of the traditional media industries. Conversely, there are some who suggest that new media giants are forming.

There is an issue with giving credit to users for the community and participation which keeps a site thriving, as the site itself has an important role in manipulating and cultivating users and communities. Youtube is a good example of this; users are guided towards particular videos or creators through algorithms which are dependent on figures that determine a video's status and rank (such as number of views, comments and likes). While users do indeed act as the judges and producers of content in both unwitting (through view count) and conscious (through comments and likes) means, the algorithms which process the numbers have a vital role; the exact mechanism of said algorithms remains undisclosed by Youtube. The websites picks 'most viewed', 'most discussed' and 'top rated' videos (picking up the format from commercial radio), but these rankings can potentially by altered or manipulated by both users and the site itself.

It shows that there are some limitations to the democratizing and decentralizing impact on media industries, and the democratizing and decentralizing impact of digitalization has not completely rebuilt the structure of media industries.

\section{CONCLUSION}

Digitalization has had an indisputable impact, especially in terms of democratizing and decentralizing, on media industries. To begin with this article introduced the background of digitalization and defined democratization and decentralization in the digital age. The article then introduced how the internet was generally regarded as a symbol of digitalization, then discussed to what degree digitalization can be seen as having a democratizing and decentralizing effect on the media industries from four key aspects. The first of these was the participation of consumers, and how it has continuously improved over the years; the shift from audiences passively receiving to actively participating; how the transformation of consumer participation has blurred the line between professional and amateur; how the media industries are trying to transform the participation of consumers to advantage themselves. Secondly, this article examined the democratizing and decentralizing effect digitalization had on media production; how the requirements of consumers has become more personalized and diversified; how interactive communication has made media companies acquire more specific consumer feedback which has helped them render a more targeted service; how the internet can be viewed as an immense database which has become the foundation of diversification of media products. In the third part of this article, the importance of consumer feedback was discussed; how it shows the traditional media magnates are beginning to lose their power; how this power is now shifting to consumers; how media enterprises have adapted to the new position by adopting a strategy of digital transformation. In the last section, this article pointed out that there are some researchers who claim that the democratizing and decentralizing influence which digitalization has brought to the media industries has been overstated; how some data suggests that only a minority of users participate in and contribute to online communities; how traditional media centres have not disappeared, but have changeed to the new form (like YouTube). It is apparent that the process of digitalization is an ongoing one; media centres are losing their power and consumer are learning how to participate in media production. However, the democratizing and decentralizing effect of digitalization has irrevocably changed the relationship between consumer and the media, 
and this in turn has fundamentally changed the structure of media industries.

\section{REFERENCES}

[1] Arthur, C., 2006. What's the 1\% Rule?. [Online]. Available at: http://technology.guardian.co.uk/weekly/ story/0,,1823959,00.html. [Accessed 3rd January 2015].

[2] Barr, T., 2000. Newmedia.com.au: The changing face of Australia's media and communications. s.l.:Allen \& Unwin.

[3] Bruns, A., 2007. Blogs, Wikipedia, Second Life and Beyond: From Production to Produsage. New York: Peter Lang Publishing.

[4] Castells, M. 1996. The information Age: Economy, Society, and Culture, Vol.1: The Rise of the Network Society, Malden, Ma and Oxford: Blackwell.

[5] Organization for Economic Co-operation and Development., 2007. Participative Web: User-generated content, s.1.: Committee for Information.

[6] Herz, J., 2005. Creative Industries. 1 ed. Victoria: Blackwell.

[7] Holmes, D. 2005. Introduction-a second media age?. In: Communication theory: Media, technology, society. pp. 1-20. London: SAGE Publications Ltd.

[8] Jenkins, H., 1992. Textual Poachers: Television Fans and Participatory Culture. New York: Routledge.

[9] IBLIOGRAPHY Lastowka, G., 2012. Minecraft as Web 2.0: amateur creativity and digital games. SelectedWorks.

[10] Livingstone, S., 2004. The Challenge of Changing Audiences. European Journal of communication, 19(1), pp. 75-86.

[11] Manovich, L., 2002. The Language of New Media. Reprint edition ed. London: The MIT Press.

[12] Miller, V., 2011. Key Elements Of Digital Media. In: Understanding Digital Culture. pp. 12-45, London: SAGE Publications Ltd.

[13] Mojang, 2015. Minecraft. [Online]. Available at: http://www.minecraft.net/. [Accessed 3rd January 2015].

[14] Negroponte, N. 1995. Being Digital. New York: Knopf.

[15] Pew Research Centre. 2013. 12 Trends Shaping Digital News. Available at: http://www.pewresearch.org/fact-tank/2013/10/16/12trends-shaping-digital-news/

[16] Poster, M., 1995. The Second Media Age. s.1.:Polity Press.

[17] Seelye, K. Q., 2005. The Times Company Acquires About.com for $\$ 410 \quad$ Million. [Online] Available at: http://www.nytimes.com/2005/02/18/business/media/18times.html [Accessed 4th January 2015].

[18] Tancer, B., 2007. Web 2.0 sites had poor user participation, Wikipedia is an exception. [Online] Available at: http://www.cnetnews.com.cn/2007/0418/387719.shtml. [Accessed 4th January 2015].

[19] Times, 2014. Minecraft is Now Part of Microsoft, and It Only Cost $\$ 2.5$ Billion. [Online]. Available at: http://time.com/3377886/microsoft-buys-mojang/. [Accessed 2nd January 2015]. 